1 Buckley EG, Williamson J. What sort of "health checks" for older people? BMF 1988;296:1144-5.

Frederiks CMA. Preventief geneeskundig onderzoek bij ouderen: pro's en contra's. Tijdschr Gerontol Geriatr 1986;17:205-8.

3 Hendriksen C, Lund E, Stromgärd E. Consequences of assessment and intervention among elderly: a three year randomised controlled trial. $B M$ 1984;289:1522-4.

4 Vetter NJ, Jones DA, Victor CR. Effect of health visitors working with elderly patients in general practice: a randomised controlled trial. $B M \mathcal{F}$ 1984;288: patients $369-72$.

5 Vetter NJ, Jones DA, Victor CR. The effectiveness of health visitors working with the elderly. Final report. Vol 1. Cardiff: Welsh National School of Medicine, 1984.

6 Rossum E van, Frederiks C, Philipsen H, Kil-van Lierop J, Mantel A Portengen J, et al. Design of a Dutch study to test preventive home visits to the elderly. Nurs Res 1991;40:185-8.

7 Rossum E van. Effects of preventive home visits to the elderly. Datawyse: Maastricht, 1993. (PhD thesis.)

8 Frederiks CMA, Wierik MJM te, Rossum HJL van, Visser APh, Volovics A Sturmans F. Why do elderly people seek professional care? Methodologies compared. I Community Health 1992;17:131-4

9 Zung WWK. A self rating depression scale. Arch Gen Psychiatry 1965;12: 63-70.

10 Qureshi KN, Hodkinson HM. Evaluation of a ten-question mental test in the institutionalized elderly. Age Ageing 1974;3:152-7.

11 Jong-Gierveld J de, Kamphuis FH. The development of a Rasch-type loneliness scale. Applied Psychological Measurement 1985;9:289-99.
12 Templeman CJJ. Welbevinden bij ouderen. Konstruktie van een meet instrument. Groningen: University of Groningen, 1987:56-82. ( $\mathrm{PhD}$ thesis.) 13 Vetter NJ, Lewis PA, Ford D. Can health visitors prevent fractures in elderly people? $B M \mathcal{F}$ 1992;304:888-90

14 Tulloch AJ, Moore V. A randomized controlled trial of geriatric screening and surveillance in general practice. $\mathcal{F} R$ Coll Gen Pract 1979;29:733-42.

15 McEwan RT, Davison N, Forster DP, Pearson P, Stirling E. Screening elderly people in primary care: a randomized controlled trial. British fournal of General Practice 1990;40:94-7.

16 CBS. Statistisch jaarboek 1992. Den Haag: SDU/uitgeverij, CBS-publikaties 1992.

17 SIG faarboek verpleeghuizen 1990. Utrech: SIG, 1991.

18 Hall N, De Beck P, Johnson D, Mackinnon K. Gutman G, Glick N. Randomized trial of a health promotion program for frail elders. Canadian fourmal of Aging 1992;11:72-91.

19 Pathey MSJ, Bayer A, Harding K, Dibble A. Randomised trial of case finding and surveillance of elderly people at home. Lancet 1992;340:890-3.

20 Harris A. Health checks for people over 75 . The doubts persist. $B M$ 1992;305:599-600.

21 Tremellen J. Assessment of patients aged over 75 in general practice. $B M$ 1992;305:621-4.

22 Brown K, Williams EI, Groom L. Health checks on patients 75 years and over in Nottinghamshire after the new GP contract. BM7 1992;305:61 9-21.

(Accepted 15 April 1993)

\title{
Accuracy of diagnosis of psychosis on general practice computer system
}

\author{
Irwin Nazareth, Michael King, Andrew Haines, Luiza Rangel, Sara Myers
}

\begin{abstract}
Objectives-To determine the accuracy of diagnoses of schizophrenia and non-affective psychosis entered by general practitioners on a computer system. To compare recording of clinical events on computer with written records.
\end{abstract}

Design-Examination of case notes of all patients with a computer diagnosis of psychosis. Search of 8000 randomly selected patient records to identify patients with psychosis not recorded on computer and comparison of 141 computer and written entries for prescribing and consultation in each practice.

Setting-13 London practices on the VAMP research bank.

Main outcome measures-Accuracy of record of psychosis compared with ICD 9, American Psychiatric Association diagnostic manual, and syndrome checklist criteria.

Results-Computer search revealed 102 patients with schizophrenia, 78 with other psychoses, and 71 with non-affective psychosis who had adequate case notes. The sensitivity and positive predictive value of the computer diagnosis of schizophrenia were $88 \%(95 \%$ confidence interval $62 \%$ to $98 \%)$ and $71 \%$ $(48 \%$ to $88 \%)$. For all non-organic psychoses sensitivity was $91 \%(74 \%$ to $97 \%)$ and positive predictive value was $91 \%(74 \%$ to $98 \%)$. On average $95 \%$ of all known prescriptions and $74 \%$ of all consultations were recorded on computer compared with $42 \%$ and $75 \%$ in written records.

Conclusions-Recording of psychotic illness on the VAMP computer is accurate and complete. Prescribing was more fully recorded on the computer than on the written records. Computer databases of well motivated general practitioners could be used for research.

\section{Introduction}

The proportion of general practices with computerised records in the United Kingdom has increased from a quarter in $1989^{1}$ to about two thirds in $1991 .^{2}$ About a third of general practices use the VAMP computer systems, which were offered to general practitioners without charge between 1987 and 1991 provided they entered data according to specified guidelines. ${ }^{3}$ The information to be recorded included demographic information, medical diagnoses, all prescriptions issued, and an indication for any newly prescribed drug. After the general practitioners had received instruction over 10-12 months the quality of the information recorded on the computer was examined. Until March 1991 practices were able to retain their computers at no cost if their data were at least $90 \%$ complete and accurate. ${ }^{4}$

After a practice has been recruited on to the VAMP research bank, the accuracy of the recorded information is monitored regularly by the company. Recent estimates suggest that data recorded by one in three VAMP practices are of research standard.' Since March 1991 computers have not been available at no cost, although practices are offered a share in the company profits. A few practices, however, provide data without any financial benefits. Practices using the VAMP system are representative of those nationwide with respect to practice profile and age and sex distribution of patients and general practitioners. Patterns of morbidity are also broadly representative. ${ }^{67}$

Although the potential of computerised information systems in large epidemiological studies has been recognised, ${ }^{8}$ doubts have been raised about the quality of data entered. ${ }^{9}$ A study comparing clinical diagnoses written in letters received from hospital consultants with diagnoses entered on computer suggested that the information was satisfactory for most clinical studies, but the diagnoses recorded by the general practitioners were not independently verified.

We conducted a study to determine the accuracy (sensitivity, specificity, and predictive value) of diagnoses for schizophrenia and non-affective psychosis entered by the general practitioners on the VAMP computers and to compare the level of recording of clinical events on the computer with the written records.

\section{Methods}

All London practices on the VAMP research bank who had $90 \%$ accurate and complete records between 1 April 1990 and 30 September 1990 were invited to 
participate. Clinical diagnoses and events are recorded by the Oxmis (Oxford Medical Information Systems) coding system..$^{10}$ These codes were developed for the computerisation of presenting problems, symptoms, and diagnoses in general practice. There are about 28000 possible entries and all can be readily cross referenced to the International Classification of Disease. ${ }^{11}$ We searched the computer for all patients with a non-organic psychosis in the following groups: schizophrenia (Oxmis codes cross referenced to ICD 9 code 295.0-295.9); other psychoses-namely, paranoid states and psychoses not otherwise specified (ICD 9 codes 297.0-297.9 and 298.0-298.9); and affective psychosis (ICD 9 codes 296.0-296.9).

VERIFICATION OF COMPUTER DIAGNOSES

The case notes of a random one in two sample of patients with schizophrenia (because of large numbers) and all patients with other psychoses and affective psychosis were examined. The information was used to make a lifetime diagnosis based on criteria for mental disorders contained in: the ninth edition of the International Classification of Diseases, ${ }^{12}$ the Diagnostic and Statistical Manual of the American Psychiatric Association, third edition revised, ${ }^{13}$ and the syndrome checklist (derived from the present state examination), which enables recording of important symptoms from case notes to make a retrospective assessment or diagnosis. ${ }^{14}$

Information was collected in a standardised manner by $\mathrm{IN}$ and SM, after which a consensus rating was made for each patient by three of us (IN, MK, and SM), MK remaining blind to the computer category of each patient. Patients were assigned a final diagnosis by using strict criteria (patients positive on ICD 9, the diagnostic and statistical manual, and the syndrome checklist) and broad criteria (patients positive on one or more of the above criteria).

\section{IDENTIFICATION OF PATIENTS NOT ENTERED ON COMPUTER}

We assessed the case notes of all patients prescribed drugs normally used to treat psychosis who were not identified as having schizophrenia, other psychoses, or affective psychosis. We also examined a selection of 8000 case notes of patients aged 16 years and over to identify all patients with psychosis who had not been entered on the computer. This sample size was calculated in order to detect, with a $95 \%$ probability, a miss rate of 0.5 patients per 1000 for an estimated prevalence of schizophrenia of 2.5 per 1000 . The search was undertaken by a single trained observer (LR). The records of all patients who seemed to have had a psychosis or who had been prescribed anti-psychotic drugs were examined in detail to determine the diagnosis.

TABLE I-Comparison of diagnosis of psychosis recorded on computer with diagnosis determined by independent assessment of case notes

\begin{tabular}{|c|c|c|c|c|c|c|}
\hline \multirow[b]{3}{*}{ Diagnosis from case notes } & \multicolumn{6}{|c|}{ Diagnosis on computer } \\
\hline & \multicolumn{2}{|c|}{$\begin{array}{c}\text { Schizophrenia } \\
(n=102)\end{array}$} & \multicolumn{2}{|c|}{$\begin{array}{l}\text { Other non-affective } \\
\text { psychosis }(n=78)\end{array}$} & \multicolumn{2}{|c|}{$\begin{array}{l}\text { Affective psychosis } \\
(n=71)\end{array}$} \\
\hline & $\begin{array}{c}\text { No }(\%) \text { of } \\
\text { patients }\end{array}$ & $\begin{array}{c}95 \% \\
\text { Confidence } \\
\text { interval (\%) }\end{array}$ & $\begin{array}{c}\text { No }(\%) \text { of } \\
\text { patients }\end{array}$ & $\begin{array}{c}95 \% \\
\text { Confidence } \\
\text { interval (\%) }\end{array}$ & $\begin{array}{c}\text { No }(\%) \text { of } \\
\text { patients }\end{array}$ & $\begin{array}{c}95 \% \\
\text { Confidence } \\
\text { interval (\%) }\end{array}$ \\
\hline \multicolumn{7}{|l|}{ Schizophrenia (ICD 9 295): } \\
\hline Strict criteria ${ }^{\star}$ & $65(64)$ & 54 to 73 & $24(31)$ & 21 to 42 & $2(3)$ & 1 to 11 \\
\hline Broad criteria $\nmid$ & $91(89)$ & 81 to 94 & $36(46)$ & 36 to 58 & $14(20)$ & 12 to 31 \\
\hline \multicolumn{7}{|c|}{ Affective psychosis (ICD 9 296): } \\
\hline Strict criteria ${ }^{\star}$ & $2(2)$ & 0.3 to 7 & $8(10)$ & 5 to 20 & $41(58)$ & 46 to 69 \\
\hline Broad criteriat & $6(6)$ & 2 to 13 & $20(26)$ & 17 to 37 & $57(80)$ & 69 to 88 \\
\hline \multicolumn{7}{|c|}{ Non-affective psychosis (ICD $9295,297,298$ ): } \\
\hline Strict criteria ${ }^{\star}$ & $87(85)$ & 76 to 91 & $49(63)$ & 52 to 73 & $5(7)$ & 3 to 16 \\
\hline Broad criteria $\nmid$ & $98(96)$ & 90 to 98 & $65(83)$ & 73 to 91 & $17(24)$ & 15 to 36 \\
\hline \multicolumn{7}{|c|}{ All non-organic psychosis (ICD 9 295-298) } \\
\hline Strict criteria ${ }^{\star}$ & $93(91)$ & 84 to 96 & $77(98)$ & 92 to 100 & $61(86)$ & 75 to 93 \\
\hline Broad criteria† & $101(99)$ & 94 to 100 & $77(98)$ & 92 to 100 & $61(86)$ & 75 to 93 \\
\hline
\end{tabular}

tMeets one or more of above criteria.
ACCURACY OF THE COMPUTER RECORD

The sensitivity of computer records for each diagnostic class was calculated by dividing the total number of patients correctly classified on the computer by the total number of patients given that diagnosis in the 8000 records searched. Specificity was calculated by dividing all patients correctly classified as not having the diagnosis by the total number of patients without that diagnosis in the 8000 records. Sensitivity and specificity were calculated for the strict and broad diagnostic criteria. These measures were used as we were judging the accuracy of the computer diagnosis against the standards applied by the research team. Measures of agreement such as $\kappa$ do not distinguish between false positive and false negative errors.

Patients with a diagnosis of schizophrenia were matched for age (in five year bands) and sex in each practice with two types of control patients as part of a more detailed study on psychosis that will be reported later. The first control was randomly selected from a pool of patients with chronic physical disease (epilepsy, diabetes, rheumatoid arthritis, and multiple sclerosis) and the second was randomly selected from the computer register. We examined a one in four sample of these records to look for systematic bias in recording of psychiatric patients. The number of computer entries made daily under presenting complaints (history display) and drugs received (treatment display), starting from the date the practice computers were accepted as being of "research standard," were compared with the written records. The number of entries made only on the computer or only on the written records was calculated by subtracting those entries common to both the computer and the written record from the total number of entries made on each of the systems. Thus, the mean proportion of total entries made only on computer or the written notes and the entries common to both were calculated.

\section{Results}

Sixteen general practices in London reached VAMP research standards during the study period and 13, comprising 28 general practitioners and 72000 patients, agreed to take part. Two single handed practices and one practice with two partners refused.

A computer search identified 212 patients with schizophrenia, 88 with other psychosis, and 78 with affective psychosis. Four patients with schizophrenia, 10 with other psychosis, and seven with affective psychosis were excluded from the analysis because of incomplete information. Table I shows the accuracy of recording for the remaining patients. The diagnoses entered on the computer by the general practitioner were based on information contained in the practice notes, which often included letters from mental health specialists, and misclassifications were more often due to diagnostic uncertainties than to incorrect computer entries. Only three of the 251 cases of psychoses were in patients who had not had contact at some time with the mental health services and in all three cases the general practitioner's diagnosis was incorrect.

One hundred and ninety four patients were treated with antipsychotic drugs and not identified on the computer. Assessment of case notes showed that 18 had a psychotic disorder, of whom three had schizophrenia, nine affective psychosis, and five an atypical psychosis. In one case the information in the case notes was inadequate for making a diagnosis.

\section{ACCURACY OF COMPUTER DIAGNOSES}

The search of the 8000 case records identified 50 patients with a probable psychosis. Thirty seven patients had already been identified by the computer 
TABLE II-Sensitivity and positive predictive value of diagnostic categorisation on computer according to strict and broad diagnostic criteria. Numbers in parentheses are $95 \%$ confidence intervals

\begin{tabular}{|c|c|c|}
\hline Computer diagnosis & $\begin{array}{c}\text { Sensitivity } \\
(\%)\end{array}$ & $\begin{array}{l}\text { Positive predicitive } \\
\text { value }(\%)\end{array}$ \\
\hline \multicolumn{3}{|c|}{ Schizophrenia (ICD 9 code 295): } \\
\hline Strict criteria ${ }^{\star}$ & $88(62$ to 98$)$ & $71(48$ to 88$)$ \\
\hline Broad criteria $\dagger$ & $71(49$ to 87$)$ & 81 (57 to 94$)$ \\
\hline \multicolumn{3}{|c|}{ Non-affective psychosis (ICD $9295,297,298$ ) } \\
\hline Strict criteria ${ }^{\star}$ & $93(74$ to 99$)$ & 81 (62 to 92$)$ \\
\hline Broad criteria & $91(74$ to 98$)$ & 93 (71 to 99$)$ \\
\hline \multicolumn{3}{|c|}{ Non-organic psychosis (ICD 9 295-298) } \\
\hline Strict criteria ${ }^{\star}$ & 91 (74 to 98$)$ & 91 (74 to 98 ) \\
\hline Broad criteria $\dagger$ & $89(74$ to 97$)$ & $100(87$ to 100$)$ \\
\hline
\end{tabular}

* Meets criteria of ICD 9, Diagnostic and Statistical Manual of Psychiatric Disorders-III, and the syndrome checklist.

tMeets one or more of above criteria.

search: 25 with schizophrenia, 10 with other psychoses, and two with non-affective psychoses.

Thirteen patients with a possible psychosis (from eight practices) had not been entered on the computer. Eight patients had not attended the practice in the previous four years and were probably not current patients of the general practitioners. We were unable to assign these patients to a diagnostic category because of inadequate information in the practice records and they were excluded from the final calculations. Assessment of the remaining five patients, by the strict criteria showed that two had an affective psychosis, one a drug related psychosis, and one an atypical psychosis. The last patient had a probable diagnosis of schizophrenia when the broad criteria were used.

Table II shows the sensitivity, specificity, predictive value for each diagnostic category with the strict and broad criteria. The specificity and negative predictive values for all categories were at least $99 \cdot 9 \%$. These measures could not be calculated accurately for affective psychosis because of small numbers.

Two of the 13 participating practices had to be excluded from this analysis as the doctors recorded all their clinical information only on computers. In each of the remaining 11 practices, 141 computerised and written records were assessed. The mean proportions of consultations and prescriptions recorded only in written notes were $27 \%$ and $5 \%$ respectively while those recorded only on the computer were $25 \%$ and $58 \%$ respectively. About half $(49 \%)$ the consultation entries and a third $(37 \%)$ of the prescribing entries were recorded on the computer and in written notes.

\section{Discussion}

Our results show that classification of psychotic illness entered on the VAMP research bank is accurate. The rate of misclassification was low and few cases were not entered on the computer by the general practitioner. The sensitivity, specificity, and predictive value of the computer categories for schizophrenia, non-affective psychosis, and all non-organic psychoses were high. These parameters were a measure not only

\section{Practice implications}

- At least two thirds of general practice records in the United Kingdom are computerised

- Information on a proportion of VAMP computer systems are recorded in a standardised fashion by motivated general practitioners

- Accuracy (sensitivity) of the diagnosis of psychosis recorded on those VAMP systems up to research standards was $88-91 \%$

- Entries relating to prescriptions issued and practice consultations were more complete on computerised records than in written notes

- Computerised systems are a useful resource in the delivery of primary health care and for research of the general practitioners' ability to key in a given diagnosis but of the ability of the doctors to decide on a diagnosis after taking into account all letters and records in the patients' notes.

The accuracy of psychiatric case registers is lower than that of these computerised records. Sensitivity for diagnosis of schizophrenia on the Camberwell case register may be as low as $50 \%$ by strict criteria. ${ }^{15}$ This has important implications for the use of databases for epidemiological and health services research and clinical trials. With 4.3 million patients on the VAMP research bank throughout England and Wales, a large potential exists for research. For example, aetiological factors in schizophrenia could be examined on a large scale with a readily selected control population. ${ }^{15}$

The completeness of record keeping on computer was high. On average, $95 \%$ of all known items issued on prescription were recorded on the computer. This may reflect the requirements of VAMP regarding accuracy of prescribing records. Although consultations by patients were recorded less consistently on the computer, two of the practices had moved to computer only records. The medicolegal implications of paperless records remain uncertain.

Although we applied the diagnostic criteria carefully, we were limited to a retrospective analysis of case notes. General practice records are, however, a rich source of data, containing the written opinions of specialists, family doctors, and allied professionals over many years. Such longitudinal diagnosis could be considered more accurate than one cross sectional clinical assessment of a patient, which is the method often used in epidemiological studies.

In conclusion, our results show that recording psychotic illness on the VAMP research bank is accurate and compares favourably with data on psychiatric registers. Prescribing was better recorded on the computer than on the written records. Thus well supported and highly motivated general practitioners' computer databases could be used for epidemiological and health service research and clinical trials.

This study was funded by the Sir Jules Thorn Charitable Trust. We thank Dr Gillian Hall, the VAMP Research Unit, and the doctors, staff, and patients of the participating practices. We also thank Sharon See Tai and Bob Blizard for statistical advice.

1 Statistics and Management Information Division, Department of Health Computing Survey 1989. London: DoH, 1989.

2 Statistics and Management Information Division, Department of Health. Computing Survey 1992. London: DoH, 1992.

3 Gray DP. Planning primary care. London: Royal College of General Practitioners, 1992. (Occasional paper 57.)

4 Jick H, Jick S, Derby LE. Validation of information recorded on general practitioner based computerised data resource in the United Kingdom. BMF 1991;302:766-8.

5 Pringle $M$. The new agenda for general practice computing. $B M 7$ 1990;301: 827-8.

6 Mann RD, Hall G, Chukwujindu J. Research implications of computerised primary care. Post Marketing Surveillance 1992;5:259-68.

7 Harrow Health District Department of Public Health. Health for all in Harrow. Annual public health report 1991. London: Harrow Health District, 1991: 4-11.

8 Marcus A. A plan for information in the National Health Service. Lancel 1988;ii:1242-3.

9 Johnson N, Mant D, Jones L, Randall T. Use of computerised general practice data for population surveillance: comparative study of influenza data. $B M^{3}$ 1991;302:763-5.

10 Perry J, ed. Oxmis problem code for primary medical care. Oxford: Oxmis Publications, 1971 .

11 World Health Organisation. Statistical classification of disease: injuries and causes of death. Vols 1,2. Geneva: WHO, 1977.

12 World Health Organisation. Mental disorders: glossary and guide to their classification in accordance with the ninth revision of the international classificaclassification in accordance with the ninh

13 American Psychiatric Association. Diagnostic and statistical manual of mental disorders (3rd ed revised). Washington, DC: American Psychiatric Association, 1987

14 Wing JK, Cooper JE, Sartorius N. Derivation of syndromes: the syndrome check list in measurements and classification of psychiatric symptoms. Cambridge: Cambridge University Press, 1974:40-7.

15 Farmer A, Wessely S, Castle D, McGuffin P. Methodological issues in using a polydiagnostic approach to define psychotic illness. $\mathrm{Br} f$ Psychiatry 1992;161:824-30.

(Accepted 21 April 1993) 